\title{
CINTILOGRAFIA DOS ESPAÇOS LIQUORICOS COM SOROALBUMINA RADIOIODADA (SARI)
}

\author{
VALTER SEIXAS * \\ Rolando Tenuto ** \\ ANNELISE Fischer-THOM*** \\ OSWALDo GNECCo *** \\ JULIO KIEFER ****
}

A investigação dos espaços subaracnóideos, iniciada como meio de visibilização direta do canal raqueano, começou há mais de 45 anos, através de investigação radiológica. Coube a Bauer e Yuhl ${ }^{1}$, em 1953, realizarem a primeira cintilografia raqueana. Depois, numerosos autores ressaltaram a oportunidade de empregar indicadores radioativos pela via ventricular, cisternal ou lombar, com o fito de colhêr informações relativas à dinâmica liquórica, à detecção de fístulas, na investigação de hidrocefalias, tanto com fins diagnósticos como para controle pós-cirúrgico, na identificação e localização de processos que determinam alteraçōes dos espaços subaracnóideos, na localização de formações tumorais expansivas, nas avulsões radiculares traumáticas, no diagnóstico e localização topográfica de hérnias de núcleos pulposos. $\mathrm{Na}$ literatura destacam-se os trabalhos de Feliciano Pinto ${ }^{9}$, Di Chiro e $\mathrm{col}^{3}, 4$, Hübner e Brown ${ }^{6}$, Perryman e col. ${ }^{8}$, Bell e Hertsch ${ }^{2}$, Dietz e col. ${ }^{5}$, sendo constante a opinião de que a cintilografia dos espaços liquóricos, embora sem oferecer a finura das imagens obtidas com os contrastes radiológicos, tem sôbre êstes a vantagem de ser melhor tolerada pelos pacientes, de não determinar seqüelas tardias, de submeter o sistema nervoso central a uma exposição radiológica por vêzes inferior às radiografias seriadas, de poder ser repetida a intervalos de tempo relativamente curtos e de utilizar indicadores de absorção rápida. A nosso ver, a qualidade inferior da imagem cintilográfica, limitada por poderes resolventes ainda não completamente satisfatórios é compensada pela maior facilidade de realização e pelas vantagens que acabamos de enumerar, recomendando-se como prova de triagem a ser realizada antes de se recorrer à exploração radiológica que seria reservada apenas àqueles casos dos quais fôsse realmente crítica, para fins diagnósticos, a obtenção de maiores e mais finos detalhes morfológicos. A opinião semelhante chegaram Hübner e col. ${ }^{6}$. Diversas substâncias marcadas pela pre-

Trabalho realizado no Departamento de Neurologia e no Laboratório de Radioisótopos da 1.\& CM (Hospital das Clinicas) da Faculdade de Medicina, Universidade de São Paulo: * Chefe de Neurocirurgia da Faculdade de Medicina do Triângulo Mineiro; ** Chefe da Secção de Neurocirurgia da FMUSP; *** Pesquisadores do Instituto de Energia Atômica e do Laboratório de Radioisótopos; **** Chefe de Pesquisa do IEA, responsável pelo Laboratório de Radioisótopos da 1.7 CM (Hospital das Clínicas). 
sença de átomo radioativo foram ensaiadas, sendo as de uso mais freqüente a albumina marcada com $\mathrm{I}^{131}$, mercuriais, PVP e insulina. O criptônio e o xenônio também foram utilizados.

Nêsse sentido, embora ainda não tenhamos experiência pessoal, acreditamos que o emprêgo de albumina marcada com tecnécio, em virtude de suas características energéticas e de sua meia vida física de apenas 6 horas, muito mais elevadas e o de câmaras de cintilação ou de "scanners" rápidos, seria certamente um indicador excelente, permitindo o emprêgo de doses objetivando melhor apreciação dos aspectos dinâmicos.

\section{MATERIAL E MÉTODOS}

Em nossos casos utilizamos a albumina I'131 (SARI) em concentraçōes de 0,5 a $1 \%$, carreando de 100 a $150 \mu \mathrm{Ci}$ por dose. Prèviamente administramos solução de lugol por via oral ou iodeto de sódio por via intravenosa. $O$ volume total de SARI injetado, em qualquer das vias utilizadas, variou entre 1 e $3 \mathrm{ml}$. Com relação a êste aspecto não repetimos quanto preconizado por $\mathrm{Di}$ Chiro e colaboradores que recorrem à injeção de volumes de indicador da ordem de até $25 \%$ do volume estimado do LCR a fim de obter rápida difusão da albumina a todos os espaços a ela acessiveis. A técnica usada já foi prèviamente descrita por um de nós ${ }^{11}$. Nas condiçōes em que operamos a difusão se faz lentamente, obtendo-se uma distribuição total, nos casos normais, decorridas 5 a 12 horas. Quando da injeção da albumina iodada, injetamos também $50 \mathrm{mg}$ de prednisolona acreditando que a mesma possa diminuir a frequêencia de reações secundárias à injeção. As reações, mais freqüentes quando se utiliza a via cisternal, limitam-se a vômitos, por vêzes cefaléia, sudorese e, para o lado do LCR, pleocitose em alguns raros casos. Jamais tivemos a lamentar seqüelas ou reações tardias.

Após a introdução do indicador radioativo procede-se ao primeiro mapeamento dentro de 2-3 horas, quando o paciente já se recuperou e não mais acusa mal estar, náuseas ou cefaléia, colaborando, portanto, mais fàcilmente. Cintilogramas realizados 6 e 24 horas depois da injeção completam o esquema de rotina. Tem-se, assim, seja qual fôr a via de introdução. informações suficientes para diagnóstico pelo menos presumptivo. A difusão do indicador radioativo se processa, quando a injeção é intracisternal, nos sentidos cranial e caudal. No sentido cranial enchem-se inicialmente as cisternas basais e os espaços subaracnóideos e, mais tarde, os ventrículos.

Esta seqüència cronológica tem preocupado a todos que he tem interessado pelo assunto e tem sugerido a existência de um fluxo liquórico que, dos ventrículos, se orientaria para os espaços subaracnóideos extracerebrais. Este sentido de corrente liquórica era interpretado aceitando-se os ventrículos como a sede da formação do LCR e as zonas mais altas dos espaços subaracnóideos como a zona de reabsorção do LCR. Este conceito parece não poder subsistir face aos trabalhos de Sweet e col. ${ }^{12}{ }_{13}$, Rieselbach e col. ${ }^{10}$. Migliori e col. ${ }^{7}$ os quais, utilizando água, eletrólitos e albumina marcados, evidenciaram que a água do LCR está em equilíbrio com a água total sistêmica, a maioria dos eletrólitos com seus respectivos espaços permutáveis e a albumina com um dos seus compartimentos extravasculares. Com relacão à albumina, tivemos oportunidade de seguir o aparecimento da albumina marcada no LCR após sua injeção no sangue, tendo esta proteína chegado a atividades específicas comparáveis com o sangue entre o $4 .^{\circ} \mathrm{e} 6 .^{9}$ dia da injeção.

O rítmo de aparecimento da albumina marcada no sangue após sua introdução no espaco subaracnóideo confirma os dados anteriores. Éstes achados nos levam a situar o espaço-LCR da albumina como parte do terceiro compartimento extravascular da mesma, o qual se caracteriza por ritmos de troca mais lentos, equilibrando, com o plasma, ao término de 5 dias. Estudos da cinética do equilíbrio entre LCR e plasma estão em curso em nosso laboratório mercê do emprêgo de dupla 
marcaçāo, pela administração simultânea de albumina $I^{131}$ no LCR e de $I^{125}$ no sangue. Como já dissemos, as indicações mais freqüentes da cintilografia dos espacos subaracnóideos prendem-se a problemas diagnósticos raqueanos. Buscam-se, geralmente, informações relativas à existência de formações expansivas bloqueadoras do canal.

Nossa casuistica compreende 25 pacientes nos quais foi feita injecão da substância radioativa no ventrículo lateral, cisterna magna ou canal lombar. A escolha do local da injeção depende da região a ser estudada. De cada paciente foram feitos 3 mapeamentos num total de 75. A SARI foi introduzida no ventriculo lateral em 5 pacientes, na cisterna magna em 2 e, no canal lombar, em 18 (tabela 1).

\section{R E S L T A D OS}

Registramos sòmente como complicações ou acidentes, pleocitose em um caso e extravazamento para o espaço peridural através do orifício de punção em outro. Doze pacientes apresentavam processos intra-raqueanos sendo 5 tumores, 4 hérnias discais lombares, 2 aracnoidites e um cisto aracnóideo no canal lombar. Nos 5 casos de tumores foi possivel determinar não só a localização exata como também os seus limites com apenas uma injeção da substância radioativa. Nos 4 casos de hérnias discais obtivemos resultados positivos com a cintilografia em apenas dois pacientes A suspeita clinica de aracnoidite em dois casos foi confirmada pelo exame cirıtilográfico, não tendo a mielografia fornecido dados positivos que pudessem facilitar o diagnóstico.

\begin{tabular}{|c|c|c|c|c|}
\hline \multirow[b]{2}{*}{ Objetivo do exame } & \multicolumn{3}{|c|}{ Local da injeção } & \multirow[b]{2}{*}{ Total } \\
\hline & intraventricular & suboccipital & lombar & \\
\hline Estudo do sistema ventricular & 5 & 一 & - & 5 \\
\hline Estudo das cisternas basais & 一 & 1 & 1 & 2 \\
\hline Estudo do canal raqueano & $\longrightarrow$ & 1 & 17 & 18 \\
\hline
\end{tabular}

Tabela 1 - Cintilografias realizadas com SARI em 25 pacientes, em relação ao local dx injeção e à sua finalidade.

No campo da patologia raqueana, se cotejarmos os resultados obtidos pela cintilografia com os decorrentes das técnicas radiológicas, verificamos que nos bloqueios completos as informações são idênticas e da ordem de $100 \%$ dos casos, cabendo à mielocintilografia a vantagem de permitir, geralmente, determinar a extensão da lesão, ou seja, seus limites superiores e inferior mercê de uma única punção (fig. 1). Nos bloqueios incompletos, as informações mielocintilográficas coincidem, com maior frequiencia com os achados cirúrgicos, dando assim vantagem a esta técnica. Já nas hérnias de núcleos pulposos a mielocintilografia, segundo Dietz e col. ${ }^{5}$, permite $\cap$ diagnóstico em apenas $30 \%$ dos casos e sua correta localização em $20 \%$, contràriamente aos achados radiológicos cujas informações são melhores em freqüência e em qualidade

No estuda da dinâmica do LCR e no das hidrocefalias, quer para fins diagnósticos quen para contrôle das corseçôes cirúrgicas realizadas, a cintilografia dos espaços liquóriøos fornece informaçōes suficientes, malgrado a imperfeição da imagem, para a interpretação dos fatos clínicos. Assim foi possivel determinar, em 5 casos de tumores intracraniamos que dificultavam o livre trânsito do LCR, a exata localizaçãa e o tipa de bloquaio (fig. 2 ). 


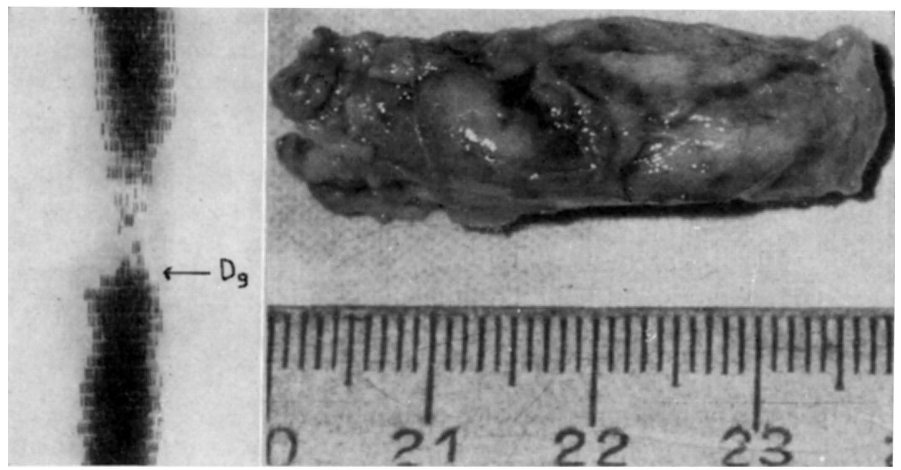

Fig. 1 - Cintilografia do canal raqueano, realizada em menino de 10 anos, demonstrando ausência de radioatividade na altura de $D_{8} / D_{9}$. O espaço correspondente a esta falha na coluna radiativa era ocupado por cisto ósseo de localização exclusivamente extradural. São identificados, neste mapeamento, os limites superior $e$ inferior do processo compressivo. A mielografia após injeção lombar de Lipiodol havia demonstrado apenas o limite inferior do processo.

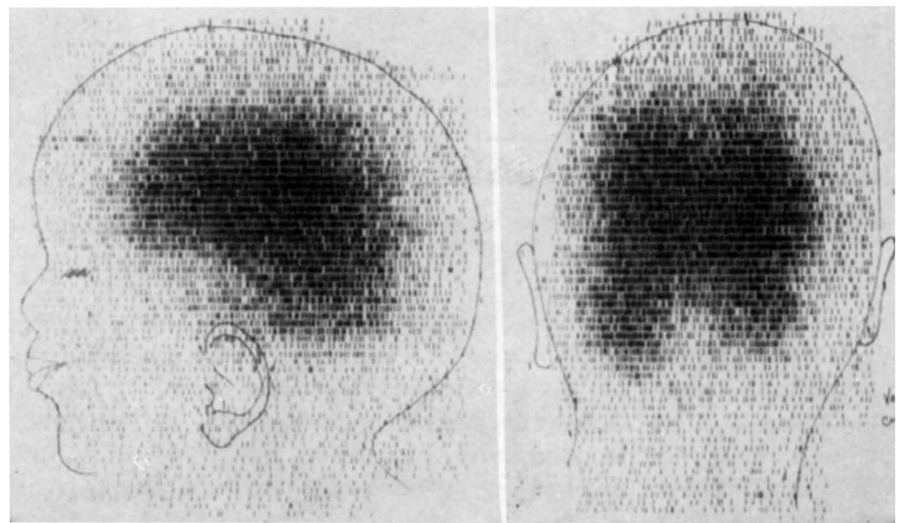

Fig. 2 - Mapeamento dos espaços liquóricos intracranianos, após injeção intraventricular de SARI, através de perfuração frontal direita. Oserva-se difusão da substancia radioativa para o ventrículo lateral do lado oposto, demonstrando a permeabilidade dos buracos de Monro. Os dois ventriculos laterais mostram-se bastante dilatados $e$ não houve passagem da substancia radioativa para o aqueduto. Tratava-se de criança de 3 anos com cisto obstruindo a porção superior do aqueduto de Sylvius. 
Nos casos em que há suspeita de fístula liquórica a cintilografia dos espacos subaracnóideos pode, eventualmente, visibilizar o trajeto fistuloso; quando isto não seja viável pela falta de resolução do método e escassez da dose injetada, é possivel controlar o aparecimento de radioatividade ao nivel do naso-faringe pela medida em "poço" de tampões de algodão trocados periòdicamente a partir da introdução intratecal de albumina.

\section{COMENTARIOS}

A título de conclusão podemos dizer, na base da experiência colhida em revisão da literatura mais recente e de nossa própria vivência do problema, que o emprêgo de indicadores radioativos, cuja difusão nos espaços subaracnóideos é acompanhada em função de tempo pela cintilografia, constitui técnica de escolha para a primeira aproximação diagnóstica e de localização para grande número de afecções do sistema nervoso central. Constitui ainda a melhor e mais inócua maneira de controlar a perviedade dos sistemas de drenagem nas correçōes cirúrgicas das hidrocefalias. No campo das afecções raqueanas avulta sua indicação pelo fato de fornecer, com uma única injeção ,os limites de lesões compressivas. Além disso seu emprêgo nos casos suspeitos de aracnoidite permite, geralmente, confirmar o diagnóstico, à diferença do que poderia ocorrer com os meios radiológicos, sem correr os riscos de agravar a moléstia pelo sequestro de contrastes.

A cintilografia dos espaços subaracnóideos não compete nem exclui as demais formas de propedêutica armada, em participar a radiologia, mas antes as completa e as indica mais formalmente, apontando ou sugerindo a existência de alterações ao livre fluxo do LCR.

\section{R E S U M O}

Os espaços liquóricos foram estudados com SARI (soroalbumina radioiodada) em 25 pacientes. Para cada um foram realizados 3 mapeamentos num total de 75. Êsses mapeamentos foram feitos 2, 6 e 24 horas após a injeção da SARI. Esta foi injetada no ventriculo lateral em 5 pacientes nos quais havia necessidade de estudar o sistema ventricular; na cisterna magna em 2, para estudo do espaço subaracnóideo intracraniano e intra-raqueano; nos outros 18 foi injetada por via lombar com a finalidade de estudar todo o canal raqueano. Os resultados obtidos pela cintilografia, comparados com aquêles fornecidos pelos exames neuroradiológicos, mostraram alto índice de positividade, tendo mesmo oferecido melhores informações em alguns dêles. Isto se verifica principalmente nas aracnoidites. Nos processos expansivos do canal raqueano pode-se, com apenas uma injeção de SARI localizar o processo e determinar seus limites. Não se observou qualquer complicação grave. Em um caso verificou-se, no LCR, uma pleocitose sem sinais clínicos e em outro, um extravazamento da substância para o espaço peridural através do orifício de punção. Trata-se, pois, de método que oferece boa segurança para o diagnóstico neurológico, não provocando complicações temíveis. 


\section{S U M M A R Y}

\section{The scintilography of the CSF-spaces by means of RIHSA}

The ventricular system and subarachnoid spaces were studied with RIHSA (radioiodinated serum albumine) in 25 patients. A total of 75 scans were drawn; 3 on each patient. These scans were drawn 2, 6 and 24 hours after having administered RIHSA. The RIHSA was introduced into the lateral ventricle of 5 patients intended for the study of the ventricular system; into the cisterna magna of two patients, in order to study the intracranial and intraspinal subarachnoid spaces; in the other 18 patients it was injected by lumbar route for the study of the spinal canal.

When the results obtained by the scintilography were compared with those shown by the orthodox neuroradiological methods the first ones showed high positivity, and even offered better information in some cases. This was especially true for the cases of arachnoiditis. It is possible to locate total or subtotal blocks of spinal canal as well as dmonstrate exactely its limits with only one intrathecal or cisternal introduction of RIHSA. No serious complications were observed. In one case o CSF pleocytosis developped without clinical symptoms; in another one, there was a leak of the substance through the puncture into the peridural space. This method offers high reliability in neurological diagnosis and does not produce serious complications.

S U S A M M E N F A S U N G

\section{Scientigraphie der Liquorräume mit radioaktiver menschlicher Serumalbumin (SARI).}

Die Liquorräume wurden mit SARI bein 25 Patienten studiert. Bei jedem Patienten wurden 2, 6 und 24 Stunden nach der Isotopeninjektion Scintigramme angefärtigt. Die SARI wurde bei 5 Patienten in den Seitenventrikel, bei 2 in die Cisterna magna und bei 18 in den lombalen Kanal injeziert. Es wurde festgestellt, dass die Scintigraphie, besonders bei Arachnoiditiden und Tumoren, gute und positive diagnostische Möglichkeiten bieten. Diese Untersuchungsmethode ermöglicht mit einer einziger Isotopeninjektion, einen raumfordernden Prozess lokalizieren und begrenzen. Auch intrakranielle Behinderungen der Liquorpassage sind bei dieser Method nachweisbar. Ernste komplikationen sind bei unseren Patienten nicht aufgetretten.

\section{R E F E R E C I A S}

1. BALER, F. K. \& YUHL, F. T. - Myelography by means of I11. Neurology (Minneapolis) $3: 341,1953$.

2. BELL, R. L. \& HERTSCH, G. H. - Automatic contour scanner for myelography. Int. J. Appl. Radiat. 7:19, 1959.

3. Di CHIRO, G.; REAMES, P. M. \& MATHEWS, W. E. - RIHSA-ventriculography and RIHSA-cisternography. Neurology (Minneapolis) 14:185, 1964. 
4. Di CHIRO, G. \& GROVE, Jr. A. S. - Evaluation of surgical and spontaneous cerebrospinal fluid shunts by isotope scanning. J. Neurosurg. 24:743, 1966.

5. DIETZ, H.; SEIXAS, V.; ZEITLER, E. \& WOLF, R. - Mielocintilografia com RIHSA-( $\left.{ }^{131}\right)$ no diagnóstico de processos patológicos intra-raqueanos. Arq. Neuro-Psiquiat. (São Paulo) 26:21, 1968.

6. HUBNER, M. D. \& BROWN, D. W. - Scanning of the spinal subarachnold space intrathecal injection of $I^{131}$ labeled human albumin. J. nucl. Med. 6:465, 1965.

7. MIGLIORE, A.; PAOLETTI, P. \& VILLANI, R. - Studies on the passage of water eletrolytes and protein into the cerebrospinal fluid in the human. Acta neurochir. (Wien) 12:1-10, 1965.

8. PERRYMAN, Ch. R.; NOBLE, P. R. \& BRAGDON, F. H. - Myeloscintilography: a useful prodedure for localization of spinal block lesions. Amer. J. Roentgenol. 80:104, 1958.

9. PINTO, F. - Mielocintilograma: contribuição à mielografia isotópica com RIHSA nos bloqueios do espaço sub-aracnoideu. Tese de docência. Impregráfica, Rio de Janeiro, 1962.

10. RIESElbaCH, R. E.; Di CHIRO, G.; FREIREICH, E. J. \& RALL, D. P. - Subarachnoid distribution of drugs after lumbar injection. New Engl. J. Med. $267: 1273,1962$.

11. SEIXAS, V. - Radioisótopos em Neurologia. In Tolosa, A. \& Canelas, H. M.: Propedêutica Neurológica. Procienx, São Paulo, 1969, pp. 495-505.

12. SWEET, W. H. \& LOCKSLEY, H. B. - Formation, flow and reabsorption of cerebrospinal fluid in man. Proc. Soc. exp. Biol. (New York), 84:397, 1953.

13. SWEET, W. H.; BROWNELL, G. L.; SCHOOL, J. A.; BOWSHER, D. R.; BENDA, P. \& STICKLEY, E. E. - The formation, flow and absorption of cerebrospinal fluid: newer concepts based on studies with isotopes. Res. Publ. Ass. nerv. ment. Dis. 34:101, 1954.

Clínica Neurológica - Faculdade de Medicina - Universidade de São Paulo Caixa Postal 3461 - São Paulo, SP - Brasil. 